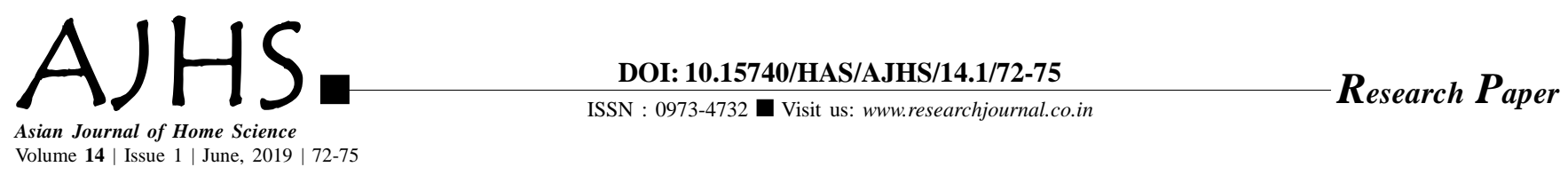

\title{
Spiral grain separator : A post harvest technology in soybean production
}

\section{Rajeshwari Desai and Priya Sajjan}

Received: 29.11.2018; Revised: 15.04.2019; Accepted: 24.04.2019

See end of the paper for authors' affiliations

\section{Rajeshwari Desai}

All India Coordinated Research

Project- Family Resource

Management, Main Agricultural

Research Station, University of

Agricultural Sciences, Dharwad

(Karnataka) India

Email : rajmanohardesaiuas

@ gmail.com
ABSTRACT : Soybean is India's one of the fastest growing crops and a significant foreign exchange earner. With a humble start of meager 0.44 million tones production in 1980-81, soybean has become a major export earner today. However, the soya industry of the country is crippled by low yield, limited domestic demand, inadequate irrigation and infrastructure. Apart from these, one of the major problems encountered in soybean production is cleaning/sorting/grading of soybean which is laborious and time consuming. Grading/sorting encourages good quality seeds/grains which eases marketing and fetches more money. With this endeavor, the present investigation was carried out with an objective to carry out field validation of improved agricultural labour saving and cost effective tool viz., spiral grain separator. Three methods of grain cleaning methods were compared with the parameters viz., time and labourers and electricity. The results showed that spiral grain separator is the best as compared to other two methods as on an average $3.5 \mathrm{q}$ of grains are cleaned per hour manually with two laborers and without electricity. It is a cost effective, labour, time and drudgery reducing farm tool and leaves the farmer free to get on with other work. Hence, there is a very great scope for spiral grain separator in soybean production which will result in improved economics of farm families.

KEY WORDS: Post harvest technology, Field validation, Spiral grain separator

- HOW TO CITE THIS PAPER : Desai, Rajeshwari and Sajjan, Priya (2019). Spiral grain separator : A post harvest technology in soybean production. Asian J. Home Sci., 14 (1) : 72-75, DOI: 10.15740/HAS/ AJHS/14.1/72-75. Copyright@ 2019: Hind Agri-Horticultural Society. 